\title{
Methodology of Echo State Neural Network To Diagnose Human Depression
}

\author{
R. Bhuvana ${ }^{1 *}$, S. Purushothaman ${ }^{2}$ and P. Rajeswari ${ }^{3}$ \\ 'Department of Computer Science, A. M. Jain College, Chennai - 600 114, Tamil Nadu, India; \\ bhuvanavr1981@yahoo.co.in \\ ${ }^{2}$ Institute of Technology, Haramaya University, Ethiopia; dr.s.purushothaman@gmail.com \\ ${ }^{3}$ Department of ECE, Institute of Technology, Haramaya University, Ethiopia; rajeswaripuru@gmail.com
}

\begin{abstract}
Depression is common in working personality due to high tension in the working environment. Symptoms can affect dayto-day life and can become very worrying. With true depression, there is a low mood and other symptoms each day for more than two weeks. Symptoms can also become rigorous enough to interfere with normal day-to-day activities. This paper suggests an Artificial Neural Network (ANN) algorithm approach for quicker learning of psychological depression data. Performance of neural network methods for estimating depression state with Echo State Neural Network (ESNN) is presented. Tentative data were collected from the patients with 21 input variables. One target output is used for training the ESNN. The training and testing patterns are made using the data as per Hamilton Rating Scale.The input patterns are pre-processed and presented to the input layer of ANN. The proposed method proves to be a capable system for diagnosis of depression.
\end{abstract}

Keywords: Depression Data, ESNN, Hamilton Rating Scale

\section{Introduction}

\subsection{Depression}

The term depression is used to explain a long period of unhappiness. It can either refer to a person's feelings where he or she is sad and depressed. To experience sadness major life crisis is must have happened. Significant depressive disorder refers to a condition where there is prolonged sadness without any link to life events. It's significant to keep in mind that major depressive disorder is an ill health and needs to be treated just like other ailments. Depression can affect a person sensitively as well as physically.

Depression $^{1}$ is a state of low mood and aversion to activity that can affect a person's feelings, manners, approach and sense of well-being. Depressed people may feel cheerless, nervous, empty, fruitless, worried, helpless, useless, guilty, irritable, hurt, or restive. They experience loss of appetite or overeating, include problems focused, detection details, or making decisions, and may perhaps contemplate or try suicide. Insomnia, extreme sleeping, collapse, loss of energy, or aches, thoroughness, or digestive problems that are resistant to management may also be present.

Depression $^{2}$ is a major contributor to the global burden of disease and affects people in all communities across the world. Depression is a common psychological disorder that presents with depressed frame of mind, loss of interest or happiness, decreased energy, feelings of guilt or low self-worth, disturbed sleep or appetite, and poor concentration. Moreover, depression often comes with symptoms of anxiety. These problems can become continual or recurrent and lead to substantial impairments in an individual's ability to take care of his or her everyday responsibilities. Depending on the number and harshness of symptoms, a depressive episode can be categorized as mild, moderate, or severe. A human being with a mild depressive episode will have some difficulty in continuing with ordinary work and social activities, but will almost certainly not cease to function altogether.

\footnotetext{
*Author for correspondence
} 


\section{Hamilton Rating Scale}

The Hamilton Rating Scale (HRS), for Depression is used for analysing depression data ${ }^{3}$. It is a multiple item questionnaire used to provide the depth of depression and as a direct measure to estimate recovery. Max Hamilton formerly provided the scale in 1960 and has demonstrated usefulness for determining the level of depression before, during, and after treatment. Higher depressive symptomatology would be discussed with relationships persisted after separate adjustments for various risk factors including sex, age, education, oral contraceptive use, dietary fat, physical activity, alcohol consumption, smoking status, LDL-cholesterol, HDLcholesterol, systolic blood pressure and history of acute infectious disease ${ }^{4}$. It is used to rate the severity of depression. In our study, the questionnaire is considered for adults The various factors considered in the rating scale are: probing mood, feelings of guilt, suicide ideation, sleeplessness, disturbance or retardation, worry, weight loss, and somatic symptoms. The HRS has 21 categories of depression ${ }^{5}$. The distribution of depression patterns used for training ESNN is given in the following Table 1.

Table 1. Distributions of patterns

\begin{tabular}{lcccc}
\hline $\begin{array}{l}\text { Total Range } \\
\text { categorized in } \\
\text { the target values }\end{array}$ & $\begin{array}{c}\text { Target } \\
\text { Values }\end{array}$ & $\begin{array}{c}\text { No. of } \\
\text { patterns } \\
\text { in each } \\
\text { category }\end{array}$ & $\begin{array}{c}\text { No. of } \\
\text { patterns } \\
\text { for } \\
\text { Training }\end{array}$ & $\begin{array}{c}\text { No. of } \\
\text { patterns } \\
\text { for } \\
\text { Testing }\end{array}$ \\
\hline$<=15$ & 1 & 49 & 9 & 9 \\
$>15$ AND $<=30$ & 2 & 786 & 18 & 18 \\
$>30$ AND $<=45$ & 3 & 903 & 18 & 18 \\
$>45$ & 4 & 62 & 10 & 10 \\
\hline Total & & 1800 & 55 & 55 \\
\hline
\end{tabular}

\section{Echo State Neural Network (ESNN)}

Artificial Neural Networks are computing elements thatare based on the structure and function of the genetic neurons. ANN has been divided into two types such as supervised and unsupervised methods. These networks have nodes or neurons that are different by difference or differential equations. Echo State Networks (ESNs) provide a novel and easier to manage approach to supervised training of RNNs. A large (order of 100s of units) RNN is used as a "reservoir" of dynamics which can be excited by suitably presented input and/or fedback output ${ }^{6}$.

RNNs are the most in nature plausible of the ANN models. RNN algorithms undergo computational complexity, resulting in instability. The problem of crumbling gradients has been addressed with special Processing Elements (PEs). It has lately become a vivid research field with numerous extensions of the basic idea, including reservoir adaptation, thus broadening the initial paradigm to using different methods for training the reservoir and the readout. That review systematically surveyed both current ways of generating/adapting the reservoirs and training different types of readouts ${ }^{7}$.

Figure 1, presents ESNN five topology interconnected. The recurrent topology of nonlinear PEs constitutes a reservoir six of rich dynamics and information about the history of input and output patterns.

In Echo State Neural Network, the ESNN possesses a highly interconnected and the recurrent topology of nonlinear processing elements called echo states (PEs). The PEs is a reservoir that stores continuous information.

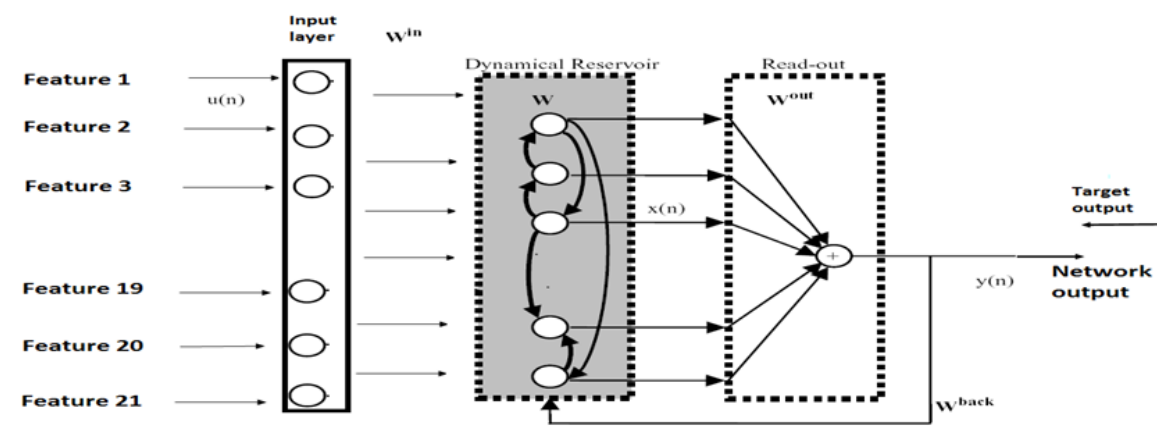

Figure 1. Echo State neural network. 
The memory less linear read out is trained to produce the output. The ESNN is presented with ' $\mathrm{M}$ ' input units, ' $\mathrm{N}$ ' internal PEs, and 'L' output units.

\subsection{Training ESNN}

Step 1: Read a Pattern (I).

Step 2: Decide the number of reservoirs.

Step 3: Deciding the number of sides in the input layer = length of the pattern.

Step 4: Decide the number of sides in the output layer = number of target values.

Step 5: Initialize random weights stuck between input and hidden layer (Ih) hidden and output.

Step 6: Calculate $\mathrm{F}=\mathrm{Ih}^{\star} \mathrm{I}$.

Step 7: Calculate $\mathrm{TH}=\mathrm{Ho}^{*} \mathrm{~T}$.

Step 8: Calculate $T T=R^{\star}$.

Step 9: Calculate $S=\tanh (\mathrm{F}+\mathrm{TT}+\mathrm{TH})$.

Step 10: Calculate $a=$ Pseudo inverse (S).

Step 11: Calculate $\mathrm{W}_{\text {out }}=\mathrm{a}^{\star} \mathrm{T}$ and store $\mathrm{W}_{\text {out }}$ for testing.

\subsection{Testing ESNN}

Step 1: Read a Pattern (I) .

Step 2: Calculate $\mathrm{F}=\mathrm{Ih}^{\star} \mathrm{I}$.

Step 3: $\mathrm{TH}=\mathrm{Ho}^{*} \mathrm{~T}$.

Step 4: $\mathrm{TT}=\mathrm{R}^{\star} \mathrm{S}$.

Step 5: $\mathrm{S}=\tanh (\mathrm{F}+\mathrm{TT}+\mathrm{TH})$.

Step 6: a = Pseudo inverse $(S)$.

Step 7: Estimated $=a^{*} W_{\text {out }}$.

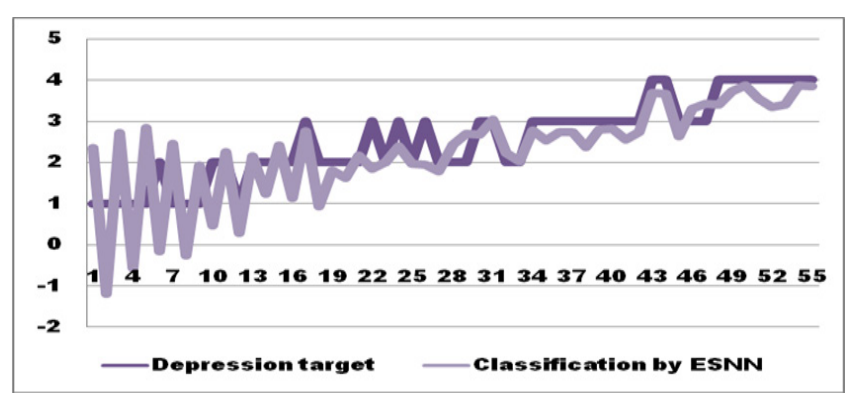

Figure 2. Classification performance of ESNN.

Table 2. Psychological Depression Data

Inputs for Artificial neural network algorithms

\begin{tabular}{|c|c|c|c|c|c|c|c|c|c|c|c|c|c|c|c|c|c|c|c|c|c|}
\hline 1 & 2 & 3 & 4 & 5 & 6 & 7 & 8 & 9 & 10 & 11 & 12 & 13 & 14 & 15 & 16 & 17 & 18 & 19 & 20 & 21 & 22 \\
\hline 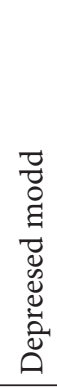 & 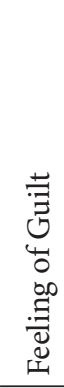 & $\begin{array}{l}\tilde{0} \\
\ddot{\Xi} \\
\tilde{B}\end{array}$ & 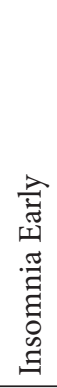 & 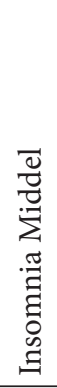 & 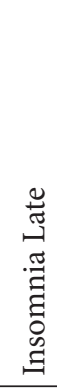 & 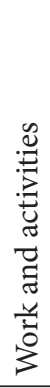 & 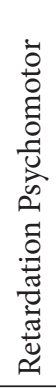 & 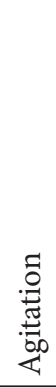 & $\begin{array}{l}\text { 离 } \\
\text { 玄 }\end{array}$ & 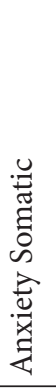 & 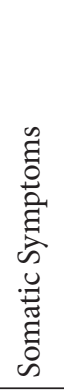 & 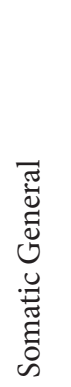 & 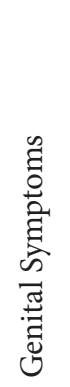 & 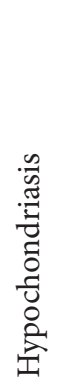 & 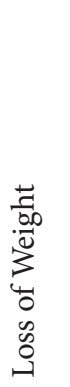 & $\begin{array}{l}\underset{\Xi}{\tilde{5}} \\
.00 \\
\Xi \\
\Xi\end{array}$ & 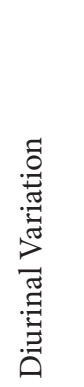 & 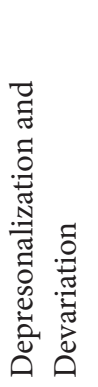 & 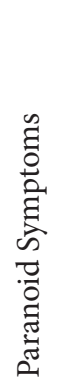 & 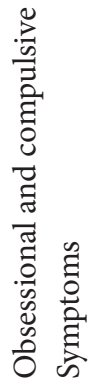 & 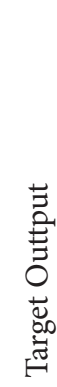 \\
\hline 0 & 0 & 0 & 0 & 0 & 0 & 0 & 0 & 0 & 0 & 0 & 0 & 0 & 0 & 0 & 0 & 0 & 0 & 0 & 0 & 0 & 0 \\
\hline 0 & 0 & 0 & 0 & 1 & 0 & 0 & 0 & 0 & 1 & 0 & 0 & 0 & 0 & 1 & 0 & 0 & 0 & 0 & 0 & 1 & 4 \\
\hline 0 & 0 & 0 & 0 & 2 & 0 & 0 & 0 & 0 & 2 & 0 & 0 & 0 & 0 & 2 & 0 & 0 & 0 & 0 & 0 & 2 & 8 \\
\hline 0 & 0 & 0 & 1 & 0 & 0 & 0 & 0 & 0 & 3 & 0 & 0 & 0 & 0 & 3 & 0 & 0 & 0 & 0 & 1 & 0 & 8 \\
\hline 0 & 0 & 0 & 1 & 1 & 0 & 0 & 0 & 0 & 4 & 0 & 0 & 0 & 0 & 4 & 0 & 0 & 0 & 0 & 1 & 1 & 12 \\
\hline 0 & 0 & 0 & 1 & 2 & 0 & 0 & 0 & 1 & 0 & 0 & 0 & 0 & 1 & 0 & 0 & 0 & 0 & 0 & 1 & 2 & 8 \\
\hline 0 & 0 & 0 & 2 & 0 & 0 & 0 & 0 & 1 & 1 & 0 & 0 & 0 & 1 & 1 & 0 & 0 & 0 & 0 & 2 & 0 & 8 \\
\hline 0 & 0 & 0 & 2 & 1 & 0 & 0 & 0 & 1 & 2 & 0 & 0 & 0 & 1 & 2 & 0 & 0 & 0 & 0 & 2 & 1 & 12 \\
\hline 0 & 0 & 0 & 2 & 2 & 0 & 0 & 0 & 1 & 3 & 0 & 0 & 0 & 1 & 3 & 0 & 0 & 0 & 0 & 2 & 2 & 16 \\
\hline 0 & 0 & 1 & 0 & 0 & 0 & 0 & 0 & 1 & 4 & 0 & 0 & 0 & 1 & 4 & 0 & 0 & 0 & 0 & 3 & 0 & 14 \\
\hline 0 & 0 & 1 & 0 & 1 & 0 & 0 & 0 & 2 & 0 & 0 & 0 & 0 & 2 & 0 & 0 & 0 & 0 & 0 & 3 & 1 & 10 \\
\hline 0 & 0 & 1 & 0 & 2 & 0 & 0 & 0 & 2 & 1 & 0 & 0 & 0 & 2 & 1 & 0 & 0 & 0 & 0 & 3 & 2 & 14 \\
\hline 0 & 0 & 1 & 1 & 0 & 0 & 0 & 0 & 2 & 2 & 0 & 0 & 0 & 2 & 2 & 0 & 0 & 0 & 1 & 0 & 0 & 11 \\
\hline 0 & 0 & 1 & 1 & 1 & 0 & 0 & 0 & 2 & 3 & 0 & 0 & 0 & 2 & 3 & 0 & 0 & 0 & 1 & 0 & 1 & 15 \\
\hline 0 & 0 & 1 & 1 & 2 & 0 & 0 & 0 & 2 & 4 & 0 & 0 & 0 & 2 & 4 & 0 & 0 & 0 & 1 & 0 & 2 & 19 \\
\hline 0 & 0 & 1 & 2 & 0 & 0 & 0 & 0 & 3 & 0 & 0 & 0 & 1 & 0 & 0 & 0 & 0 & 0 & 1 & 1 & 0 & 9 \\
\hline 0 & 0 & 1 & 2 & 1 & 0 & 0 & 0 & 3 & 1 & 0 & 0 & 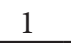 & 0 & 1 & 0 & 0 & 0 & 1 & 1 & 1 & 13 \\
\hline
\end{tabular}


In the ESNN network, the number of nodes/ reservoirs has to be decided that decides the classification performance of ESNN. Figure 2 presents the performance of ESNN in classifying the depression data based on the sample data presented in Table 2. X-axis represents pattern numbers and $y$-axis represents to the category, the pattern is classified.

\section{Conclusion}

The Echo state neural network has been used to estimate the depression category based on the depression data collected base don Hamilton rating scale. The work proves to be an efficient system for diagnosis of depression. The collected data can be correlated with the commercial psychological database. Many ANN algorithms can be used to estimate the depression category.

\section{References}

1. Sher L, Mann JJ, Traskman-Bendz L, Winchel R, Huang YY, Fertuck E, Stanley BH. Lower cerebro-spinal fluid homo- vanillic acid levels in depressed suicide attempters. J Affect Disord. 2006; 90(1):83-9.

2. Elovainio M, Keltikangas-Jarvinen L, Kivimaki M, Pulkki L, Puttonen S, Heponiemi T, Juonala M, Viikari JS, Raitakari OT. Depressive symptoms and carotid artery intima-media thickness in young adults: The cardiovascular risk in young finns study. Psychosomatic Medicine. 2005; 67(1):522-30.

3. Hamilton M. A rating scale for depression. Journal of Neurology and Neurosurgery. 1960; 23:56-61.

4. Elovainio M, Keltikangas-Jarvinen L, Pulkki-Raback L, Kivimaki M, Puttonen S, Viikari L, Rasanen L, Mansikkaniemi K, Viikari J, Raitakari OT. Depressive symptoms and Creactive protein: The cardiovascular risk in young finns study. Psychological Medicine. 2006; 36(1):797-805.

5. Bhuvana R, Purushothaman S, Rajeswari P, Balaji RG. Development of combined back propagation algorithm and radial basis function for diagnosing depression patients. Int J Eng Tech. 2015; 4(1):244-9.

6. Jaeger $H$. The "echo state" approach to analysing and training recurrent neural networks. GMD Report 148, GMD-German National Research Institute for Computer Science. 2001.

7. Lukosevicius $\mathrm{M}$, Jaeger $\mathrm{H}$. Reservoir computing approaches to recurrent neural network training. Computer Science Review. 2009; 33:127-49. 